\title{
Anodal and cathodal pulsed electrical stimulation on skin wound healing in guinea pigs
}

\author{
Fereshte Ghayebi Mehmandoust, MSc; ${ }^{1}$ Giti Torkaman, PhD $;^{1 *}$ Mohammad Firoozabadi, PhD; ${ }^{2}$ Gadamali \\ Talebi, MSc ${ }^{1}$ \\ Departments of ${ }^{1}$ Physical Therapy and ${ }^{2}$ Medical Physics, Tarbiat Modares University, Tehran, Iran
}

\begin{abstract}
We investigated the effects of anodal and cathodal electrical stimulation on wound healing. In a randomized controlled trial, we divided 42 male albino guinea pigs into two control (C1 and C2) and four experimental (E1-E4) groups. A $3 \mathrm{~cm}$ linear incision was made at the dorsal skin of all guinea pigs. A unidirectional pulse current of 300 to 600 microamperes, $80 \mathrm{pps}$, and $0.3 \mathrm{~ms}$ pulse duration was administered for 1 hour a day. In groups E1 and E3 (anodal), a positive polarity was applied for the first 3 days followed by negative polarity the remaining days. In groups E2 and E4 (cathodal), negative polarity was applied for the first 3 days and positive polarity the remaining days. Groups E1, E2, and C1 were killed on day 14 and E3, E4, and C2 on day 21. We measured the percentage of decrease in wound surface area (daily tracing) and tensile strength (on days 14 and 21). The results indicated that both cathodal and anodal stimulations increased the rate of wound closure. Beginning with day 12, we saw a significant difference in the percentage of the decrease in wound surface between all treatment and control groups $(p<0.05)$. Ultimate tensile strength and stress increased in the anodal compared with the cathodal and control groups; at the end of day 14, ultimate tensile stress in E1 was significantly greater compared with C1 $(p<0.05)$. We conclude that electrical stimulation, regardless of polarity regimen, benefits wound healing, but anodal stimulation the first 3 days and cathodal stimulation the remaining days can lead to stronger repaired tissue.
\end{abstract}

Key words: anodal stimulation, cathodal stimulation, electrical stimulation, guinea pig, microamperage current, rehabilitation, skin, tensile strength, unidirectional pulse current, wound healing.

\section{INTRODUCTION}

An effective means of promoting wound healing is electrical stimulation [1-4]. Despite many studies on wound healing, the application of electrical stimulation is still in its infancy because of the varied and inconsistent modes of stimulation used and results obtained among the studies [1-2]. An important parameter of electrical stimulation in wound healing is the type of applied polarity, which may affect protein synthesis, cell migration, growth of bacteria, galvanotaxis, inflammation, edema, and also the processes of bioelectric events of injury [1-2,5].

Through the years, different methods regarding the type of polarity have been used in research studies; in some, constant positive or negative polarities were applied throughout the healing period [6-8]. But most recent studies varied the type of treatment polarity during the healing process [9-12]. Rowley et al. [13] and Barranco et al. [14] showed that negative polarity has antibacterial effects. Kloth and McCulloch [1], Castillo et al. [8], and Alvarez et al. [15] suggested the use of positive polarity to

Abbreviations: \% $\downarrow$ WSA $=$ percentage of decrease in wound surface area, $F_{\max }=$ ultimate tensile strength.

*Address all correspondence to Giti Torkaman, PhD; PO Box 14115-331, Ale-Ahmad, Department of Physical Therapy, Tarbiat Modares University, Tehran, Iran; +98-21-88011001, ext 4509; fax: +98-21-88006544. Email: torkamg@modares.ac.ir DOI: 10.1682/JRRD.2007.01.0007 
augment the migration and proliferation of epithelial cells and therefore hasten wound closing. Based on the antibacterial effect of negative polarity and the epithelialization effect of positive polarity, Brown et al. [9] and Bayat et al. [12] used negative polarity for the first 3 days and positive polarity for the remaining days of their studies.

Barker et al. [16] and Foulds and Barker [17] showed in both human and animal models that the external surface of the intact skin possesses a negative charge with respect to the deep epidermal layers. Ojingwa and Isseroff [3], Burr et al. [18], and Vodovnik and Karba [19] showed that during a skin injury, the normal situation is changed and a current of injury occurs and causes the wound to be positively charged.

Vodovnik and Karba [19], Hampton and King [20], and Nuccitelli [21] suggested that the endogenous bioelectric current of the wound has a regulatory role in the wound-healing process and that the use of exogenous electrical stimulation may mimic this endogenous current and improve wound healing.

In vitro and in vivo studies have reported that the application of positive polarity has some useful effects, including destruction of microorganisms [22], increased migration and proliferation of the epithelial cells $[1,15]$, increased attraction of macrophage cells to the wound site [1,23], and better simulation of endogenous currents of the wound [24]. Also, some useful effects of negative polarity include killing microorganisms [13-14], removing necrotic tissues due to decreasing $\mathrm{pH}$ of the wound environment [25], limiting protein molecule infiltration and therefore limiting formation of edema in the injury site [26], and increasing fibroblast cell proliferation and collagen synthesis [27-28].

Therefore, each of the current polarities on the wound site appear to be able to improve some parts of the healing processes, but until now, the most appropriate protocol for polarity application to improve wound healing was unknown.

Three basic treatment regimens for wound healing are commonly used today: direct current, pulsed current, and alternating current [29]. Pulsed current is a mechanism that reduces the electrothermal and electrochemical hazards of direct current application [29]. To investigate the effect of electrical stimulation on the attraction of positively or negatively charged cells toward an electric field of opposite polarity, we used unidirectional pulsed current (squared pulse).
In this study, we investigated and compared the effects of negative polarity the first 3 days followed by positive polarity the remaining days and vice versa on wound closing and the biomechanical parameters of wound tissue. We have not seen this protocol used in any other study.

\section{MATERIALS AND METHODS}

\section{Subjects}

We used 42 healthy male albino guinea pigs (Dunkin-Hartley; Pasteur Institute of Iran, Tehran, Iran) that were 4 to 6 months old and weighed 300 to $400 \mathrm{~g}$. The animals were maintained in special cages under controlled conditions according to the experimental guidelines of Tarbiat Modares University. Up to 12 hours before the surgery, the animals had unlimited access to food. The Ethical Commission of Tarbiat Modares University approved the study.

\section{Surgical Procedure}

After weighing the animals, we prepared the anesthesia using a mixture of xylazin $(20 \mathrm{mg} / \mathrm{mL})$ and ketamine hydrochloride ( $100 \mathrm{mg} / \mathrm{mL}$; 1 to $8 \mathrm{cc}$, injection of $1 \mathrm{cc} / \mathrm{kg}$ ) [9]. The hair on the middle part of the back of the guinea pig was shaved and then the area was antisepticised with betadine. Following the sterilization, we made a fullthickness incision, $3 \mathrm{~cm}$ long at a distance of $1 \mathrm{~cm}$ from the spine, on the right side of the paravertebral region (Figure 1). Twenty-four hours after the incision, we measured the size of the wound surface using transparent

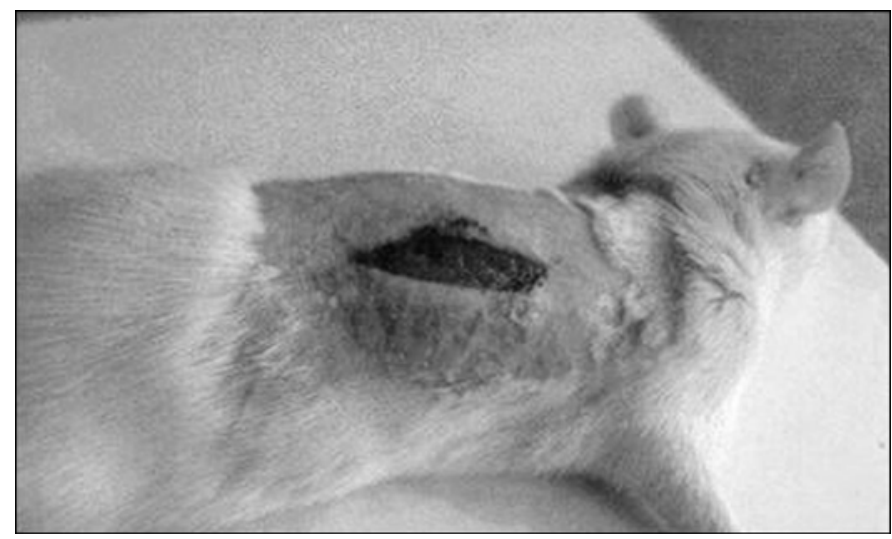

Figure 1.

Sample of full-thickness skin wound on guinea pig 1 day after incision. 
plastic paper and used the obtained measurements for the calculations subsequently described in the "Measurement Procedures" section.

\section{Treatment Protocols}

The animals were randomly divided into six groups: two control groups (C1 and C2) and four experimental groups (E1-E4). Each control group contained five animals and each experimental group contained eight. The C1 group was studied for 14 days and the C2 group for 21 days. The four experimental groups (E1-E4) consisted of two groups that were studied for 14 days (E1 and E2) and two groups that were studied for 21 days (E3 and E4). In E1 and E3 (anodal), positive polarity was applied over the wound for the first 3 days and then negative polarity for the rest of the treatment period. In E2 and E4 (cathodal), negative polarity was applied for the first 3 days and then positive polarity for the rest of the treatment period. In all control and experimental groups, electrodes were similarly placed on the wound site, but the current applied in C1 and C2 was zero. Treatment began 24 hours after the wound was induced. Through an isolator device (model ss 104-j; Nihon Kohden Corporation, Shinjuku-ku, Tokyo, Japan), we applied the calibrated current to the animal's skin. Interrupted unidirectional pulsed current was used daily for 1 hour; this squared pulse had a frequency of $80 \mathrm{~Hz}$ and duration of $0.3 \mathrm{~ms}$, with an intensity between 300 and $600 \mu \mathrm{A}$. These stimulation parameters were used in a previous study and found to provide a comfortable treatment that is well tolerated by animals [30-31]. Afterward, the animals were immobilized with a restrainer device and then stimulated for 1 hour. The electrical current was applied 1 hour daily and continued for 14 or 21 days, based on group. Carbon rubberized electrodes $\left(2 \times 3 \mathrm{~cm}^{2}\right)$ were placed on sterile pads moistened with saline solution. The active electrode (cathode or anode, depending on group) was placed on the incision (wound area) and the inactive electrode was placed on the opposite-site shaved area, $5 \mathrm{~cm}$ proximal from the wound.

\section{Measurement Procedures}

The percentage of decrease in wound surface area

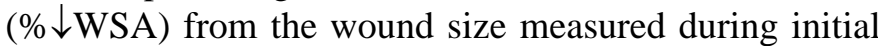
evaluation was calculated for each animal. To improve the accuracy of these measurements, we traced each wound three times. Tracing was performed with transparent plastic paper. The area was calculated by planimetry. We identified the tracings by code numbers to exclude observer bias. We also recorded the day that the wound area closed in order to calculate the time required for wound closing. After completion of the treatment period, the animals were killed by inhalation of chloroform and tissue samples were collected for use in the tensiometry test. The E1, E2, and C1 groups were killed on day 14 and the E3, E4, and C2 groups on day 21. The tissue samples, which were 5 to $7 \mathrm{~cm}$ long and $3 \mathrm{~cm}$ wide, were taken vertically to the initial incision. To avoid measurement errors caused by tissue differences among the animals of each group and to establish an intra-animal control for higher precision [32], we took from each animal a wound sample and a sample of adjacent healthy skin. We used the latter sample to normalize the biomechanical characteristics of the wound. To reduce tissue changes and preserve the natural condition of the tissues, we placed the samples in a normal saline solution $(0.9 \%)$ before tensiometry testing [12].

The uniaxial tensile test was performed by tensiometer (model Z 2.5; Zwick Gmbh \& Co, Ulm-Einsingen, Germany). The rate of the tensile test was $20 \mathrm{~mm} / \mathrm{min}$. After the test, load-deformation and stress-strain curves were obtained [33]. To evaluate the efficacy of different protocols, we measured and analyzed the parameters of (1) ultimate tensile stress (newtons/square millimeter), derived from the ultimate load divided by the original unstrained cross-sectional area; (2) ultimate tensile strength $\left(F_{\max }\right)$ (newtons), the load that causes a structure to fail; and (3) the area under the load-deformation curve (newton millimeters), the amount of work done by the deforming load.

\section{Data Analysis}

After the data collection, we normalized the measures related to stress and $F_{\max }$ using the Equation

Normalized Data $=\frac{\text { Intra-Animal Control Data }- \text { Wound Sample Data }}{\text { Intra-Animal Control Data }}$

After normalizing, we used the Kolmogorov-Smirnov test to identify the normal distribution. The results showed that the data had normal distribution. One-way analysis of variance and an independent-samples $t$-test were used to compare the data related to ultimate tensile stress, $F_{\max }$, area under load-deformation curve, duration of wound closure, and \% $\downarrow$ WSA on various days among the groups. 


\section{RESULTS}

The wound surface and biomechanical parameters were analyzed. We evaluated the tissue tensile strength by the variables $F_{\max }$ (ultimate tensile strength), stress (ultimate tensile stress), and area under load-deformation curve (work to $F_{\max }$ ).

\section{Wound Area Measurements}

\section{Percentage of Decrease in Wound Surface Area}

As already mentioned, to normalize the available differences in initial wound size among groups, we expressed the measurements of the wound surface as $\% \downarrow W S A$. The $\% \downarrow$ WSA from the wound size measured during the initial evaluation was calculated for each subject.

1. In the 14-day groups, the $\% \downarrow W S A$ was greater in E1 and E2 than in C1 from day 12 on $(p<0.05)$. (Table 1).

2 . In the 21-day groups, the \% $\downarrow$ WSA in E3 and E4 significantly differed from C2 from day 12 on $(p<0.05)$ (Table 2).

\section{Duration of Wound Closure}

1. On day 14, the wound had not closed completely in any group.

2. On day 21, the duration of wound closure in E3 and E4 significantly differed from C2 $(p<0.05)$, but no significant difference was seen between E3 and E4 (Figure 2).

Table 1.

Wound area parameters (mean \pm standard deviation) in 14-day experimental (E) and control (C) groups.

\begin{tabular}{lccc}
\hline \multicolumn{1}{c}{ Parameter } & \multicolumn{3}{c}{ Group } \\
\cline { 2 - 4 } & Anodal (E1) & Cathodal (E2) & Control (C1) \\
\hline \% $\downarrow$ WSA & & & \\
Day 12 & $81.1 \pm 10.2^{*}$ & $91.8 \pm 6.4^{*}$ & $56.9 \pm 3.8$ \\
Day 14 & $93.7 \pm 4.8^{*}$ & $98.8 \pm 2.9^{*}$ & $82.5 \pm 3.2$ \\
Normalized Stress (N/mm ${ }^{2}$ ) & $0.4 \pm 0.2^{*}$ & $0.5 \pm 0.1$ & $0.8 \pm 0.2$ \\
Normalized $\boldsymbol{F}_{\text {max }}(\mathbf{N})$ & $0.31 \pm 0.30$ & $0.32 \pm 0.30$ & $0.64 \pm 0.20$ \\
Normalized Area Under Load-Deformation Curve (N.mm) & $0.06 \pm 0.09$ & $0.10 \pm 0.09$ & $0.23 \pm 0.08$ \\
\hline
\end{tabular}

*Significantly different from control group, $p<0.05$.

$\% \downarrow$ WSA $=$ percentage of decrease in wound surface area, $F_{\max }=$ ultimate tensile strength.

Table 2.

Wound area parameters (mean \pm standard deviation) in 21-day experimental (E) and control (C) groups.

\begin{tabular}{|c|c|c|c|}
\hline \multirow{2}{*}{ Parameter } & \multicolumn{3}{|c|}{ Group } \\
\hline & Anodal (E3) & Cathodal (E4) & Control (C2) \\
\hline \multicolumn{4}{|l|}{$\% \downarrow$ WSA } \\
\hline Day 14 & $97.1 \pm 3.4^{*}$ & $89.1 \pm 14.9^{*}$ & $69.7 \pm 11.0$ \\
\hline Day 16 & $98.2 \pm 3.1^{*}$ & $95.4 \pm 5.9^{*}$ & $79.1 \pm 8.2$ \\
\hline Normalized Stress $\left(\mathrm{N} / \mathrm{mm}^{2}\right)$ & $0.56 \pm 0.19$ & $0.57 \pm 0.26$ & $0.71 \pm 0.25$ \\
\hline Normalized $F_{\text {max }}(N)$ & $0.34 \pm 0.33$ & $0.57 \pm 0.14$ & $0.53 \pm 0.26$ \\
\hline Normalized Area Under Load-Deformation Curve (N•mm) & $0.10 \pm 0.10$ & $0.17 \pm 0.08$ & $0.096 \pm 0.16$ \\
\hline Duration of Wound Closure (d) & $16.1 \pm 0.7^{*}$ & $17.6 \pm 0.8^{*}$ & $21 \pm 0$ \\
\hline
\end{tabular}


3. The wound surfaces closed faster in E3 and E4 than in $\mathrm{C} 2$.

\section{Tissue Biomechanical Parameters Measurements}

We report the results related to the normalized amounts of ultimate stress, $F_{\text {max }}$, and area under loaddeformation curve. Note that all tensile strength testing measurements were performed at the end of days 14 and 21. The smaller normalized amounts obtained indicate that the actual amounts of the parameter are greater. The amounts of biomechanical parameters are expressed as normalized parameters in Tables 1 and 2.

\section{Tissue Ultimate Tensile Stress}

1. On day 14, the normalized amount of tensile stress was significantly different between E1 and C1 $(p<$ 0.05), but no difference was seen between groups E1 and E2. E2 and C1 were not statistically significantly different (Figure 3).

2. On day 21, the averaged normalized amount of ultimate tensile stress was greater in anodal group E3 and cathodal group E4 than in control group C2, but this difference was not statistically significant (Table 2).

\section{Ultimate Tensile Strength}

1. On day 14, the normalized amount of $F_{\max }$ was smaller in E1 with respect to the E2 and C1, but this difference was not statistically significant (Table 1).

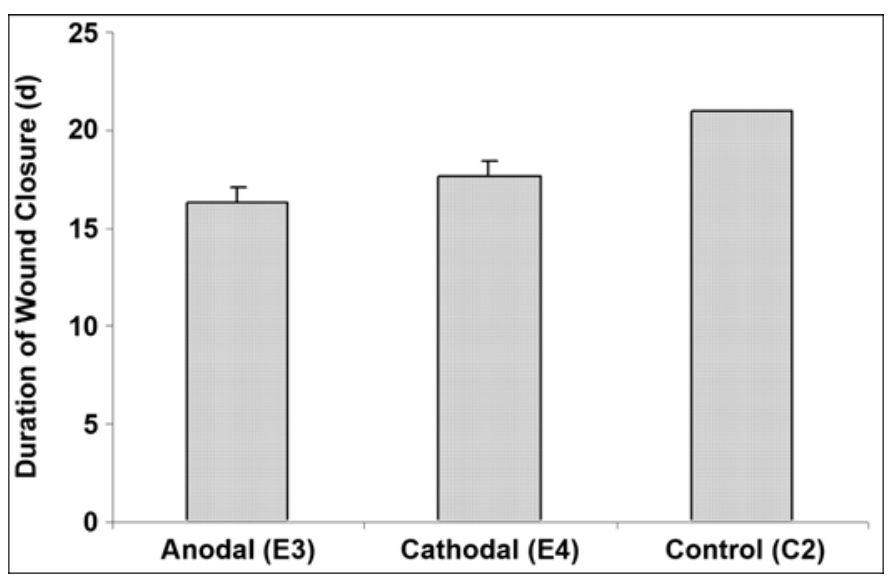

Figure 2.

Duration of wound closure (mean \pm standard error of the mean) on day 21 in experimental (E) and control (C) groups.
2. On day 21, the normalized amount of $F_{\max }$ was smaller in E3 with respect to E4 and C2, but this difference was not statistically significant (Table 2).

\section{Area Under Load-Deformation Curve}

1. On day 14, the normalized amount of area under the load-deformation curve (up to the peak point) was smaller in E1 compared with $\mathrm{C} 1$, but this difference was only marginally significant $(p=0.06)$. The difference between E1 and E2 was not statistically significant (Table 1).

2. On day 21, no difference in normalized amount of area under the load-deformation curve was observed among the E3, E4, and C2 groups.

\section{DISCUSSION}

This study compared the effects of two basic protocols of applied stimulus polarity on healing of skin wounds at two different time points. Important findings concerning wound surface area were obtained on days 14 and 21; a difference in $\% \downarrow$ WSA was observed among all treatment versus control groups, and this difference was significant from day 12 on.

Based on the results of this study, the application of electrical stimulation, regardless of the applied polarity regimen, can lead to greater and faster decreases in wound surface area.

Assimacopoulos [6] in 1968 and Bigelow et al. [7] in 1979 reported that the application of a negative direct

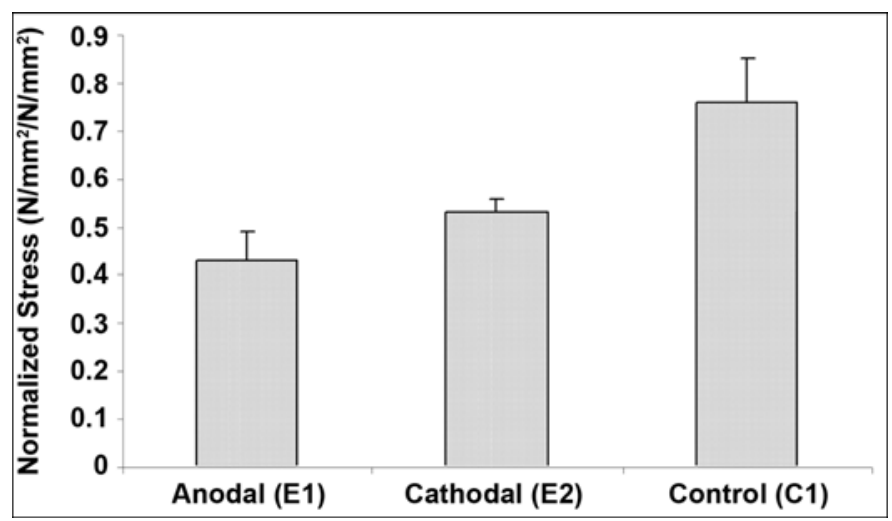

Figure 3.

Normalized amount of tensile stress (mean \pm standard error of the mean) on day 14 in experimental (E) and control (C) groups. 
current, with respect to control group, caused greater decrease and faster closing of the wound surface. In 1983, Alvarez et al. used a positive polarized current and reported that after 4 days, wound epithelialization occurred faster in the stimulated animal group than in a control group [15]. The findings of Brown et al. [9] in 1995, Taskan et al. [11] in 1997, and Demir et al. [34] in 2004 showed that the use of negative polarity for the first 3 days followed by positive polarity during the remaining study period caused a greater decrease of the wound surface, with respect to a control group.

As mentioned in the "Introduction" section, each of the treatment polarity regimens appears to be able to induce useful changes in the wound healing process; in other words, both the positive and negative polarities can improve some parts of the healing process and therefore prepare the condition for better and faster healing. Similar to the findings of other studies, the results of this study show that electrical stimulation, regardless of the polarity regimen used, has meaningful effects on the decrease in wound surface area and the duration of wound closure.

Brown et al. evaluated the effect of different regimens of polarity application and reported that the use of negative polarity for the first 3 days followed by positive polarity significantly affects wound surface closing [35].

Taskan et al. [11] and Demir et al. [34] used negative polarity for the first 3 days and then positive polarity up to the end of their study periods and reported that electrical stimulation with related protocols shortens the inflammatory stage and hastens healing progression into the proliferation stage. On the other hand, the effect of positive polarity on attraction and greater proliferation of epithelial cells is reported in various articles [1,3-4,35]. On day 14 of our study, the amount of the ultimate tensile stress in E1 compared with C1 significantly increased. Even though the amount of ultimate tensile stress and $F_{\text {max }}$ were greater in E1 with respect to E2, these differences were not significant. Regarding galvanotaxic effects of negative polarity in attraction and proliferation of fibroblast cells [27-28], electrical stimulation application in E1 appeared to cause more attraction and proliferation of fibroblast cells in the wound site. Normally, by the second or third day after wounding, fibroblast cells begin to proliferate and synthesize collagen fibers, raising collagen levels continually for approximately 3 weeks [36]. So, the use of negative polarity in the anodal groups
(E1 and E3) after day 3 appears to have caused greater collagen synthesis.

A comparison of the results of day 21 showed that ultimate tensile stress and strength in the anodal group E3 with respect to two other groups (E4 and C2) were greater but not significantly so. Comparison of the findings in all anodal experimental groups showed that the collagen deposit appears to be greater and to cause an increase in early breaking strength of the wound tissue, but after day 21, the amount of collagen itself cannot make a significant difference in the tensile strength of the wound tissue. Increased tissue strength during the remodeling stage of healing is mainly associated with proper alignment of collagen fibers [37]. The absence of proper alignment made no significant difference, and electrical stimulation with the given protocol in this study did not seem to affect the tissue maturation or orientation of the collagen fibers.

Histological studies should be performed to confirm these findings especially for collagen density and alignment. One should note that although no significant difference was seen in the tissue breaking strength between groups at the end of day 21, this result does not preclude the use of electrical stimulation in skin wounds because, based on the results of this study and other works, electrical stimulation can improve the breaking strength of the wound at the earlier stages. Since the skin wound is more susceptible to further damage during the proliferation stage, increasing the wound strength and hastening wound closure can better protect the granulated tissue and wound against rupture and infection, which are very important clinically. This beneficial effect will be important in chronic nonhealing wounds that do not respond to standard care. The recent decision of the Centers for Medicare and Medicaid Services to allow reimbursement for electrical stimulation treatment of chronic ulcers means that the dermatologic practitioner will likely become more familiar with this novel treatment approach and that wound-care centers will include this option for recalcitrant ulcers [29].

\section{CONCLUSIONS}

The results of this study indicate that electrical stimulation, regardless of polarity regimen, can lead to significantly decreased wound surface and earlier closure. Applying electrical stimulation according to the parameters 
given in this study for at least 12 days appears to lead to a significant difference in wound surface decrease, but applying anodal stimulation on the first 3 days and then following with negative polarity for the rest of the treatment period may lead to stronger repaired tissue.

To better understand the affecting mechanisms of electrical stimulation on the wound healing process, we further suggest measuring electrical potential at the wound site throughout healing and evaluating biochemical and histological factors.

\section{ACKNOWLEDGMENTS}

We acknowledge with gratitude Dr. Tim Watson, who reviewed this article and gave us some beneficial comments.

Gadamali Talebi is now at the Tabriz University of Medical Sciences, Iran.

This material is the result of work supported with resources and the use of facilities at the Tarbiat Modares University.

The authors have declared that no competing interests exist.

\section{REFERENCES}

1. Kloth LC, McCulloch JM. Promotion of wound healing with electrical stimulation. Adv Wound Care. 1996;9(5): 42-45. [PMID: 9069747]

2. McCulloch JM, Kloth LC, Feedar JA. Wound healing: Alternatives in management. 1st ed. Philadelphia (PA): F. A. Davis Company; 1990. p. 221-56.

3. Ojingwa JC, Isseroff RR. Electrical stimulation of wound healing. J Invest Dermatol. 2003;121(1):1-12. [PMID: 12839557

4. Weiss DS, Kirsner R, Eaglstein WH. Electrical stimulation and wound healing. Arch Dermatol. 1990;126(2):222-25. [PMID: 2405781]

5. Kloth LC. Electrical stimulation for wound healing: A review of evidence from in vitro studies, animal experiments, and clinical trials. Int J Low Extrem Wounds. 2005; 4(1):23-44. [PMID: 15860450]

6. Assimacopoulos D. Wound healing promotion by the use of negative electric current. Am Surg. 1968;34(6):423-31. [PMID: 5651495]

7. Bigelow JB, Al-Husseini SA, Vonrecum AF, Park JB. Effect of electrical stimulation on canine skin and percutaneous device-skin interface healing. In: Brighton CT, Black J, Pol- lack SR, editors. Electrical properties of bone and cartilage: Experimental effects and clinical applications. New York (NY): Grune \& Stratton, Inc; 1979. p. 289-310.

8. Castillo E, Sumano H, Fortoul TI, Zepeda A. The influence of pulsed electrical stimulation on the wound healing of burned rat skin. Arch Med Res. 1995;26(2):185-89.

[PMID: 7620286]

9. Brown M, Gogia PP, Sinacore DR, Menton DN. Highvoltage galvanic stimulation on wound healing in guinea pigs: Longer-term effects. Arch Phys Med Rehabil. 1995; 76(12):1134-37. [PMID: 8540790]

10. Feedar JA, Kloth LC, Gentzkow GD. Chronic dermal ulcer healing enhanced with monophasic pulsed electrical stimulation. Phys Ther. 1991;71(9):639-49. [PMID: 1881954]

11. Taskan I, Ozyazgan I, Tercan M, Kardas HY, Balkanli S, Saraymen R, Zorlu U, Ozügül Y. A comparative study of the effect of ultrasound and electrostimulation on wound healing in rats. Plast Reconstr Surg. 1997;100(4):966-72. [PMID: 9290665]

12. Bayat M, Asgari-Moghadam Z, Maroufi M, Rezaie F, Bayat M, Rakhshan M. Experimental wound healing using microamperage electrical stimulation in rabbits. J Rehabil Res Dev. 2006;43(2):219-26. [PMID: 16847788]

13. Rowley BA, McKenna JM, Chase GR, Wolcott LE. The influence of electrical current on an infecting microorganism in wounds. Ann N Y Acad Sci. 1974;238:543-51. [PMID: 4216282]

14. Barranco SD, Spadaro JA, Berger TJ, Becker RO. In vitro effect of weak direct current on Staphylococcus aureus. Clin Orthop Relat Res. 1974;(100):250-55. [PMID: 4838406]

15. Alvarez OM, Mertz PM, Smerbeck RV, Eaglstein WH. The healing of superficial skin wounds is stimulated by external electrical current. J Invest Dermatol. 1983;81(2): 144-48. [PMID: 6308102]

16. Barker AT, Jaffe LF, Vanable JW. The glabrous epidermis of cavies contains a powerful battery. Am J Physiol. 1982; 242(3):R358-66. [PMID: 7065232]

17. Foulds IS, Barker AT. Human skin battery potentials and their possible role in wound healing. Br J Dermatol. 1983; 109(5):515-22. [PMID: 6639877]

18. Burr HS, Harrey SC, Taffel M. Bio-electric correlate of wound healing. Yale J Biol Med. 1940;2:103.

19. Vodovnik L, Karba R. Treatment of chronic wounds by means of electric and electromagnetic fields. Part 1. Literature review. Med Biol Eng Comput. 1992;30(3):257-66. [PMID: 1453797]

20. Hampton S, King L. Healing an intractable wound using bio-electrical stimulation therapy. Br J Nurs. 2005;14(15): S30-32. [PMID: 16144075]

21. Nuccitelli R. A role for endogenous electric fields in wound healing. Curr Top Dev Biol. 2003;58:1-26.

[PMID: 14711011] 
22. Kincaid CB, Lavoie KH. Inhibition of bacterial growth in vitro following stimulation with high voltage, monophasic, pulsed current. Phys Ther. 1989;69(8):651-55. [PMID: 2501804]

23. Orida N, Feldman JD. Directional protrusive pseudopodial activity and motility in macrophages induced by extracellular electric fields. Cell Motil. 1982;2(3):243-55. [PMID: 6816471]

24. Karba R, Semrov D, Vodovnik L, Benko H, Savrin R. DC electrical stimulation for chronic wound healing enhancement. Part 1. Clinical study and determination of electrical field distribution in the numerical wound model. Bioelectrochem Bioenerg. 1997;43(2):256-70.

25. Newton RA, Karselis TC. Skin $\mathrm{pH}$ following high voltage pulsed galvanic stimulation. Phys Ther. 1983;63(10): 1593-96. [PMID: 6604927]

26. Bettany JA, Fish DR, Mendel FC. Influence of cathodal high voltage pulsed current on acute edema. J Clin Electrophysiol. 1990;2:5-8.

27. Erickson CA, Nuccitelli R. Embryonic fibroblast motility and orientation can be influenced by physiological electric fields. J Cell Biol. 1984;98(1):296-307. [PMID: 6707093]

28. Yang WP, Onuma EK, Hui SW. Response of C3H/10T1/2 fibroblasts to an external steady electric field stimulation. Reorientation, shape change, ConA receptor and intramembranous particle distribution and cytoskeleton reorganization. Exp Cell Res. 1984;155(1):92-104. [PMID: 6541591]

29. Ojingwa JC, Isseroff RR. Electrical stimulation of wound healing. J Invest Dermatol. 2003;121(1):1-12. [PMID: 12839557]
30. Lundeberg TC, Eriksson SV, Malm M. Electrical nerve stimulation improves healing of diabetic ulcers. Ann Plast Surg. 1992;29(4):328-31. [PMID: 1466529]

31. Wood JM, Evans PE, Schallreuter KU, Jacobson WE, Sufit R, Newman J, White C, Jacobson M. A multicenter study on the use of pulsed low-intensity direct current for healing chronic stage II and stage III decubitus ulcers. Arch Dermatol. 1993;129(8):999-1009. [PMID: 8352625]

32. Goldestein B, Sanders J. Skin response to repetitive mechanical stress: A new experimental model in pig. Arch Phys Med Rehabil. 1998;79(3):265-72. [PMID: 9523777]

33. Zeng YJ, Xu CQ, Yang J, Sun GC, Xu XH. Biomechanical comparison between conventional and rapid expansion of skin. Br J Plast Surg. 2003;56(7):660-66. [PMID: 12969664]

34. Demir H, Balay H, Kirnap M. A comparative study of the effects of electrical stimulation and laser treatment on experimental wound healing in rats. J Rehabil Res Dev. 2004;41(2):147-54. [PMID: 15558369]

35. Brown M, McDonnell MK, Menton DN. Polarity effects on wound healing using electric stimulation in rabbits. Arch Phys Med Rehabil. 1989;70(8):624-27. [PMID: 2788400]

36. Cukjati D, Robnik-Sikonja M, Rebersek S, Kononenko I, Miklavcic D. Prognostic factors in the prediction of chronic wound healing by electrical stimulation. Med Biol Eng Comput. 2001;39(5):542-50. [PMID: 11712650]

37. Stadelmann WK, Digenis AG, Tobin GR. Physiology and healing dynamics of chronic cutaneous wounds. Am J Surg. 1998;176(2A Suppl):26-38S. [PMID: 9777970]

Submitted for publication January 15, 2007. Accepted in revised form March 23, 2007. 